DOI: 10.17805/zpu.2015.3.15

\title{
Интенсификация сбыта высокомаржинальных низколиквидных товаров путем бартерных транзакций (на примере арт-бизнеса)
}

\author{
И. А. ГОЛЬМАН \\ (МОСКОВСКИЙ ГУМАНИТАРНЫЙ УНИВЕРСИТЕТ)
}

В статье выделен и исследован в качестве отдельного класса рыночных продуктов кластер высокомаржинальных низколиквидных товаров и услуг (ВНТУ). Рассмотрены общие проблемы интенсификации сбыта подобных продуктов с точки зрения практикующего маркетолога, в том числе с учетом кризисных явлений в экономике. Актуальность темы связана с тем, что объем российского рынка ВНТУ исчисляется десятками миллиардов рублей и стремится к дальнейшему росту. В то же время именно этот кластер наиболее болезненно чувствителен к кризисным явлениям в экономике. Автор рассматривает метод интенсификации сбыта ВНТУ путем использования бартерных транзакций. Показаны механизмы бартерных операций с ВНТУ, их достоинства и недостатки.

В качестве примера ВНТУ взят современный российский арт-бизнес с его основной продукцией - живописью и графикой. Рассуждения и выводы автора основаны на результатах его экономических экспериментов, в том числе бартерных транзакций в современном российском арт-бизнесе. На конкретных примерах показаны плюсы и минусы этого метода интенсификации сбыта, включая как возможность увеличения и ускорения продаж, так и рост трудоемкости процесса, необходимость новых компетенций персонала, дополнительные проблемы с налогообложением и возможность репутационных потерь.

Введена градация бартерных товаров по степени их ликвидности и даны примеры выстраивания бартерных цепочек. Сделан вывод на базе собственного опыта автора, что при умелом использовании бартерные транзакции способны существенно увеличивать экономическую эффективность, причем не только арт-бизнеса, но и всего кластера ВНТу.

Ключевые слова: маркетинг, высокомаржинальные низколиквидные товары, кластер ВНТУ, бартер, бартерные транзакции, арт-рынок.

\section{BВЕАЕНИЕ}

ктуальность темы исследования определяется ее практической значимостью
в том, что кластер высокомаржинальных низколиквидных товаров и услуг (ВНТУ) се-
годня исчисляется десятками миллиардов рублей при устойчивой тенденции к росту.
В то же время любой экономический кризис прежде всего бьет именно по этому кла- 
стеру, в результате чего задача интенсификации сбыта часто становится вопросом выживания бизнеса. Ситуация усугубляется тем, что современные исследователи рынка мало уделяют внимания новым методам интенсификации сбыта подобных товаров. Если же в качестве представителя ВНТУ брать современный арт-бизнес, то можно говорить о практически полном отсутствии отечественных научных наработок по этой теме.

Но вначале определимся с тем, что автор подразумевает под высокомаржинальными низколиквидными товарами. Это класс товаров и услуг (точнее - классы), объединенных двумя главными свойствами. Первое - себестоимость их производства (оказания) должна быть в несколько раз, а то и в десятки, сотни раз меньше реальной рыночной цены (подчеркиваю: реальной, т. е. такая цена должна быть подтверждена не единичными актами продаж, а множественными желательно разнесенными во времени и географии сбыта). Второе неотъемлемое свойство ВНТУ (для определенности остановимся на товарах) - их относительно невысокая ликвидность, что, безусловно, напрямую связано с первым рассмотренным свойством этих товаров.

Как правило, наиболее значительную часть цены ВНТУ представляет не материальная составляющая (состав, стоимость создания, доставки и сбыта), а имиджная бренд, имя автора, принадлежность к истории и т. д.

Например, ювелирные украшения компании «Штерн» могут стоить в несколько раз дороже точно таких же (по составу, внешнему виду и обработке) небрендовых ювелирных изделий. То же самое можно сказать о дорогих часах, высокой моде (цена изделия из ткани выше, чем такой же по весу объем золота), шоу-бизнесе (гонорары одинаково одаренных вокалистов могут отличаться в тысячи раз), работе киноактеров, премиумных марках мебели и автомобилей.

Кстати, далеко не все эти товары и услуги низколиквидны. Например, знаменитый вокалист, как правило, имеет расписание туров на годы вперед, пока его популярность не снизится либо не вырастет конкуренция.

Тем не менее за редкими исключениями общее правило таково: чем выше маржинальность товара или услуги, тем ниже ее ликвидность.

Особенно это заметно в арт-бизнесе, в секторе современного изобразительного искусства. Поскольку автор давно изучает на практике современный арт-бизнес, то было бы логично и тему сегодняшнего исследования связать с указанной областью рынка. Тем более что изыскания автора всегда в конечном счете направлены на поиски практических механизмов повышения эффективности бизнеса.

В предыдущих статьях, опубликованных в журнале «Знание. Понимание. Умение», автор уже рассматривал условия, при которых арт-инвестор вправе рассчитывать на эффективность своего бизнеса на современном российском арт-рынке. В моих статьях были проанализированы свойства искусства как рыночного товара; рассмотрены взаимоотношения основных участников арт-рынка, а также принципы коммерческого продвижения арт-объектов и их авторов; даны практические рекомендации по выбору художников для последующего инвестирования в их творчество; сформулирован необходимый минимум знаний и умений для этого; показано, что в данной бизнес-среде действуют известные законы и принципы маркетинга, применимы его стандартные процедуры (разумеется, с учетом описанной в указанных выше статьях специфики сегмента рынка) (Гольман, 2013a; 2013b; 2014a; 2014b). Соответственно, применим и маркетинговый опыт - как базовый (см.: Котлер, 1990), так и адаптированный к российской действительности (см.: Гольман, 2004). 
В указанных выше статьях давалось определение арт-объектов, предлагаемых на рынке, как товара Алительного пользования с высоким маржинальным потенциалом и неявной потребительской стоимостью. Аля произведений подавляющего большинства современных художников я, можно сказать, доформулировал это определение, добавив к «неявной потребительской стоимости» еще и «заведомо невысокую ликвИАНОсть».

Кроме того, я подчеркивал, что успешная реализация высокомаржинальных объектов искусства невозможна без продвижения (брендирования) самого автора этих произведений.

Здесь необходимо принципиально важное уточнение: речь и в предыдущих работах, и в нынешнем исследовании идет исключительно о современных, не имеющих большой известности авторах, работающих на российском арт-рынке. Хотя чрезвычайно важно понимать, что, даже став известным, коммерчески успешным автором, художник рискует потерять много, если не все, когда по каким-либо причинам прекращается маркетинговая поддержка его деятельности. Таких примеров даже в текущем российском арт-бизнесе уже достаточно. Один из продвигаемых нами в настоящее время художников А. В. Павлов был весьма коммерчески успешен в конце 90-х годов прошлого века. У него были множество персональных выставок, известность, зарубежные творческие поездки (во Вьетнам, Францию и т. А.), хорошие продажи. Все это кончилось с прекращением промотирования за пару лет, и в середине первого десятилетия нового века, когда мы начали работать с этим художником, нам практически все пришлось начинать сначала. В том числе - и по ценам продаваемых работ. Та же история произошла с художником М. И. Бирюковым. Совсем недавно, в 2007-2008 гг., у него были успешные продажи на ряде заметных западных аукционов. После чего многолетний коммерческий провал на фоне прекращения промотирования.

Мне показалась полезной и содержательной запись в дневнике на интернет-форуме В. Богданова «Неудачные инвестиции в искусство» (Богданов, 2013: Электронный ресурс), в которой рассмотрены случаи потери вложенных средств и по уже весьма дорогим художникам.

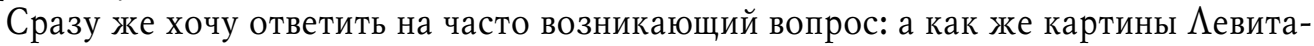
на, Шишкина, не говоря уже про работы Ван Гога, Рафаэля или Аюрера? Разве они неликвидны?

Конечно, ликвидны. Отдельный вопрос, во сколько обойдется счастливцу, нечаянно нашедшему неизвестную картину Рафаэля, путь от собственно находки до аукциона. Гарантирую, что не дешево. Но главное - работы признанных мастеров, «порхающие» по заметным аукционам планеты, не являются ни высокомаржинальными, ни низколиквидными. Это просто другой товар, совершенно не имеющий отношения к тому, о котором мы сейчас рассуждаем.

Аля конкретизации рассмотрим работы замечательного художника И. А. Сапункова, на которого я уже ссылался в предыдущих статьях. Ао начала промотирования цена больших листов ( 40 × 60 см и крупнее) его великолепной графики (чаще всего смешанная техника) была менее 1000 руб. за единицу. С учетом таланта автора, качества работ и трудоемкости их исполнения это - ничто. Что, впрочем, не мешало редким потенциальным покупателям отчаянно торговаться с продавцом его работ.

Так вот, первый же аукцион (Сапунков Игорь: Электронный ресурс), на который попала его работа ( «Рыбак на озере», 40×60, бумага, акварель, тушь, чернила), выявил совсем другую цену «ухода» - 30000 руб. Интересно, что когда я подошел к покупа- 
телю и предложил ему бесплатно сделать сертификат подлинности на приобретенную работу, тот отказался. Сказал, что это ему не нужно, он откликнулся сердцем, без инвестиционных целей. Реакция в коммерческом плане совершенно не корректная, однако вполне по-человечески понятная: именно за радость общения с искусством покупатели и отдают свои деньги.

Аалее, мы занялись коммерческим продвижением талантливого художника и одновременно с этим росли цены продаж его работ. Сегодня однозначно можно сказать, что качественную графику И. А. Сапункова ни за 500 руб., ни за 5000 руб. купить не удастся. Таким образом, цена рассматриваемого товара (прошу прощения за применение маркетингового термина к высокому искусству) сформировалась в десятки раз выше, чем была всего несколько лет назад.

Но следует ли из этого, что мы одновременно можем вывести на аукцион, скажем, 50 работ этого автора и все их дорого продать? К сожалению, нет. А 100 работ? (Мы в начале пути приобрели обширный архив автора). Тем более нет.

Итак, мы пришли к странному на первый взгляд выводу.

Если держатели фонда работ талантливого современного художника решат их разом продать по сегодняшней «аукционной» цене, то это окажется архисложной задачей. Возможно, даже невыполнимой в разумные сроки.

Однако если кто-то решит дешево купить работы данного автора, даже оптом у него тоже ничего не получится. Никто дешево не продаст.

Этот парадокс и есть описание на примере понятия высокомаржинального низколиквидного товара.

Таким образом, он действительно стоит дорого и скорее всего всегда будет стоить дорого (бывает снижение цены при заведомо спекулятивных действиях с художником либо при внезапном прекращении промотирования, что, впрочем, не меняет сути явления принципиально). Купить такой товар дешево невозможно. Однако, как указано выше, и продать такой товар непросто, особенно в больших количествах.

Причин тому несколько.

Он не является товаром первой необходимости. Он очень сильно зависит от вкусов потенциального покупателя. И наконец, он находится в конкурентном окружении товаров той же товарной группы, но в десятки и сотни раз дешевле. На Вернисаже в Измайлово лист «подобной» графики (обратите внимание на кавычки) по-прежнему может продаваться за 1000 руб.

Разница лишь в том, что работы признанного мастера постепенно все же будут продаваться, - пусть и не так часто, как хотелось бы, - по достойной цене. А поделки с рынка - столь же редко, но по низкой.

Кстати о Вернисаже. В начале пути, в соответствии со своим эмпирическим подходом, автор решил практически изучить и этот сегмент арт-рынка. Соответственно арендовал место и честно отстоял на «Вернике» (сленг старожилов) все без исключения выходные дни одного календарного года, включая 31 декабря. Практически ничего не продал, но получил колоссальную массу полезных знаний. Самое печальное из них - стояние на таком рынке быстро убивает настоящий талант. Аело в том, что неподготовленные ценители покупают у отдельно взятого художника всегда очень дешево и практически всегда одно и то же. В итоге автор превращается в подобие плоттера, создающего на пяти мольбертах сразу один и тот же сюжет - так меньше краски расходуется. Пишу об этом не с юмором, а с болью, потому что одновременно художник расходует свой полученный свыше дар, причем, как правило, безвозвратно. 
Именно поэтому в договорах художника с арт-инвестором не должно быть прописано никакого творческого давления. Художник сам решит, что ему делать. Если он действительно художник.

Итак, подведем промежуточный итог.

ВНТУ можно охарактеризовать достаточно точно следующим образом: это товар, который дешево не купишь, и много дорого не продашь. Понемногу, разумеется, продается постоянно: репутация наработана, и цена не с потолка взята.

Ключевое слово здесь - «много».

Но если продавать мало, то рентабельность бизнеса может оказаться под большим вопросом (что и подтверждается массовым закрытием галерей).

Ааже если картины выкуплены галеристом заранее, обеспечивая ему очень высокую маржинальность единичной сделки. Ведь из полученных от продажи средств нужно платить зарплату сотрудникам, за аренду помещения, за выставки и каталоги, выплачивать налоги и т. д. Если относить эти затраты на себестоимость только проданных за отчетный период картин, то товар уже сложно будет назвать высокомаржинальным. Хотя он по-прежнему остается низколиквидным. Собственно, в этом и кроется причина массовой финансовой гибели галерей.

Выходов в таких ситуациях, как всегда, два.

Первый - все бросить, и начать новую жизнь. Без торговли предметами искусства и связанных с этим проблем. Если же прежняя жизнь устраивает во всем, кроме денег (нет ничего дучше, чем проводить каждый новый день рядом с любимыми картинами), то следует подумать об иных путях интенсификации сбыта.

Один из них - старый спутник всех экономических кризисов и смутных времен бартер.

Кратко рассмотрим его достоинства и недостатки. Единственное реальное достоинство бартера заключается в следующем: товар, который по каким-либо причинам сложно было продать за деньги, часто гораздо легче обменять на другие товары и услуги. Это обстоятельство легко объяснимо. Во-первых, желающих получить нужное в обмен на какие-то свои имеющиеся активы всегда гораздо больше, чем желающих купить за деньги. Во-вторых, бартерная сделка по обоюдным розничным или обоюдным оптовым ценам позволяет участникам получать в свое распоряжение чужой товар с учетом той прибыли, которая была заложена в цене его собственного товара. Аругими словами, мало того что контрагенты получают чужой товар не за «живые» деньги, так еще и за меньшую реальную стоимость.

B-третьих, избавляясь от ненужных, залежавшихся товаров, экономишь на собственных накладных расходах. Разумеется, при условии, что, избавляясь от ненужного, получаешь нужное.

Главный же недостаток бартера - это лишнее маркетинговое звено в традиционной цепочке «товар - деньги - товар», в данном случае - между создателем картины и ее приобретателем. (Хотя при приобретении по бартеру необходимого товара, т. е. без последующей его перепродажи, цепочка, наоборот, сокращается - из нее исчезают «деньги», что делает сделку более экономичной.) Но обычно бартерный товар также подлежит перепродаже - со своей собственной трудоемкостью, себестоимостью и особенностями, которые мало кому из участников арт-рынка известны.

Почему так происходит - понятно: редко удается найти прямой бартер, устраивающий одновременно обе стороны мены. Когда, скажем, Пиросмани писал картины в обмен на обед. Или художник отдает картину, а получает холсты и краски. Или от- 
дает картину взамен места для экспозиции своих работ на выставке (кстати, последний пример бартера традиционен для арт-бизнеса). А если ему за картину предлагают центнер велосипедных подшипников?

Но главная трудность все же указана ранее - художник, решивший заняться бартером, влезает в тысячи новых отношений, знаний и проблем.

Мой вывод в этой связи абсолютно категоричен.

Художнику вообще не следует самостоятельно заниматься бизнесом, а тем более таким специфическим, как бартерные сделки. На мой взгляд, художник должен хорошо разбираться в арт-бизнесе, хотя бы на уровне, изложенном мной в статье (Гольман, 2013а). Это позволит ему правильно (т. е. взаимовыгодно, не сдавая себя в рабство и в то же время не пытаясь, ничем не рискуя, доминировать) строить отношения с арт-инвестором и галеристами.

А вот последние в качестве операторов рынка вполне могли бы заняться бартерным подкреплением своего арт-бизнеса.

Главный недостаток, разумеется, все равно остается - большая лишняя трудоемкость и необходимость в дополнительных компетенциях. И если галерист круглые сутки обслуживает поток покупателей в своей галерее, то бартер ему противопоказан.

А вот если «поток» состоит из двух-пяти посетителей (не покупателей!) в день (стандартный трафик галереи, а иногда и того меньше), то имеет смысл сменить сонное существование на более энергичное.

Вернемся к нашему опыту.

Методика продвижения арт-объектов и их автора (брендинг) при использовании бартера сильно не меняется (Гольман, 2013b, 2014a), но в спектре ваших коммерческих предложений появляется опция товарного обмена.

Наши эксперименты показывают, что продать объекты искусства бартером действительно гораздо проще, чем прямой продажей. Количественно - примерно на порядок как по числу актов продаж, так и по сумме средней сделки.

Вот основные аргументы контрагентов нашей галереи, подвигающие их к заключению бартерного контракта (разумеется, может быть и комбинация из нескольких аргументов, что еще более ускоряет принятие решения):

1. Свободных денежных средств нет, а залежавшиеся складские запасы есть.

2. Аеньги жалко, а сэкономить на складе даже приятно.

3. Всегда хотел приобрести хорошие работы, но возможность бартерной транзакции встретил впервые.

4. Аиквидируем товарное направление, поэтому обменять товары на искусство дешевле, чем хранить уже ненужное.

5. Предприятие закрывается, нужно срочно вывезти товары.

6. Предлагаемый для бартера товар (или услуги) тоже высокомаржинален, что позволяет получить предметы искусства реально во много раз дешевле.

7. Впервые встречаем такое предложение, поэтому просто интересно попробовать.

8. Предлагаемый товар или услуги просто пропадут, если не будут обменяны.

9. Предлагаемый к бартеру на картины товар «неисчерпаем» (ниже поясним, что под этим подразумевается).

Пример в п. 8 чаще связан с услугами, чем со скоропортящимися товарами. Скажем, турагентству с экскурсионным автобусом почти без разницы, обслужить 30 или 35 человек, лишь бы не пришлось заказывать еще один автобус и дополнительное 
гостиничное размещение. Если тур будет недозагруженным, эти пять мест все равно пропадут.

Аналогичное положение у фитнес-клубов, ресторанов, кинотеатров и т. А., где добавление полезной нагрузки (в определенных объемах) практически не увеличивает уже понесенные затраты.

В примере п. 9 имеется в виду вот что: например, песчаный карьер обычно имеет запасы на много лет выработки, иногда - на десятки. И лишние пять-десять самосвалов не сделают его владельца ни беднее, ни богаче.

Есть другой вариант иллюстрации этого пункта.

Возьмем, скажем, типографию. Все художники обязаны пользоваться ее услугами Аля печати своих каталогов и рекламных материалов. У большинства типографий ярко выраженная сезонность. В спокойное время почему бы не оказать услугу по бартеру? Все равно аренда идет, зарплаты выплачиваются, а машинам от простоя только хуже.

Аокументооборот и налоговые потери при бартере можно сократить, используя возможности действующего законодательства. Так, если галерея оформлена как магазин на патенте, то при бартере никаких дополнительных выплат не последует, даже кассовый аппарат не нужен.

Если картины на товар меняет индивидуальный предприниматель по упрощенной системе налогообложения, то будьте готовы заплатить налог со стоимости полученного за картины товара. На сегодня это 6\% с суммы договора, которая определяется по согласию сторон. Если товар необходим для прямого потребления галереей, то результат отличный и налоговая нагрузка незначительна. Но если предстоит бартерная цепочка, чтобы выйти на нужный товар, то за каждое ее звено налог придется заплатить отдельно и выйдет весьма накладно.

В этом случае идеально использование встречных договоров купли-продажи между предприятиями, работающими с учетом налога на добавленную стоимость: к уплате не начислят ни НАС, ни налог на прибыль до тех пор, пока бартерный товар не будет продан конечному покупателю.

Разумеется, в Устав галереи должен быть добавлен пункт об оптовой и (или) розничной торговле.

Ну и теперь ключевой вопрос, который возникнет у галериста или арт-инвестора: а что делать с самосвалами песка, контейнером подшипников или 10000 березовых веников, которые внезапно стали вашими? Ответ один - продавать. Если, конечно, не можете использовать их напрямую с пользой для своего предприятия.

А как продать товар, который даже опытные прежние владельцы продавать затруднялись? Здесь опять только один рецепт - цена.

Ведь мы начали с того, что наш «родной» товар - брендированное современное искусство - высокомаржинальный, т. е. мы останемся в прибыли, даже дав большую скидку. Без высокой маржинальности в начале бартерного процесса подобный бизнес становится бессмысленным, кроме варианта прямого бартера, когда выменивается заранее необходимый товар. Отсюда побочный, однако очень важный вывод: брендирование художника и его работ так же важно при бартерной схеме, как и при обычной. Пожалуй, даже важнее: теоретически можно дешево, но много сбывать no name-картины ${ }^{1}$ как элемент доступного декора. Но в схеме с бартером, который еще предстоит с потерей маржинальности продать, такой вариант вообще неприемлем.

При этом важно отметить, что, уменьшив в два раза цену на картину, вы не сильно увеличите сбыт, но убьете рыночную репутацию художника. Обменяв же по самой вы- 
сокой цене картину на товар и заметно уменьшив цену при продаже этого товара, вы не нанесете репутационного ущерба никому, поскольку картина была оценена высоко, а бартерный товар случаен, и случайная сделка никак не влияет на рыночные цены.

Впрочем, про возможный репутационный ущерб от бартерных операций с ВНТУ следует сказать особо. В каком бы экономическом положении ни находилась ваша арт-галерея (или любой иной продавец ВНТУ), категорически нельзя ни менять ВНТУ на другой, более ликвидный товар по явно заниженной цене, ни продавать полученный по бартеру товар с чрезмерно высокими, явно нерыночными скидками. И то и другое мощно ударит по репутации ВНТУ, а, как сказано выше, высокая маржинальность товаров в данном сегменте рынка обеспечена как раз именно репутацией предлагаемого продукта. Не будет репутации - не будет ВНТУ.

Теперь продолжим про возможные варианты действий с бартерным товаром. Например, когда у арт-инвестора накапливается большое количество и номенклатура товаров, возможно выгодное выстраивание бартерных цепочек. Однако при этом потребуется склад, логистика и т. А., т. е. дополнительные затраты труда и денег. И нужно всякий раз считать, что выгоднее по деньгам и трудозатратам.

Здесь следует отметить еще один важный момент, замеченный автором на практике. Это уже касается любого бартерного бизнеса - как с арт-составляющей, так и без оной. При использовании бартерных сделок кроме главной задачи - извлечения прибыли обязательно возникает еще одна, вспомогательная, но постоянная задача бартерная конвертация товарных запасов в сторону повышения их ликвидности при сопоставимой глубине Аисконта. Это легко пояснить на конкретном примере. Скажем, картины - типичный высокомаржинальный низколиквидный товар. Аюстры, бра и торшеры - более ликвидны, чем картины. Еще более ликвидна домашняя утварь. А автомобили продать вообще небольшая проблема (напоминаем, что речь идет о продаже бартерных товаров с сопоставимым дисконтом). И наконец, возьмем автомобильное топливо, которое по большому счету практически биржевой товар, и его быстрый сбыт гарантирован даже с самым небольшим дисконтом.

Таким образом, несложно ранжировать товар по степени ликвидности при наличии сопоставимого дисконта. Здесь зависимость та же, что и отмеченная нами ранее: чем маржинальность товара ниже, тем, как правило, ликвидность выше.

Аругими словами, можно разделить все обилие возможных бартерных товаров на, допустим, пять классов: наименьшая ликвидность - класс 5; наивысшая - класс 1.

Тогда бартерная стратегия может выглядеть следующим образом.

Шаг 1. Обмен картин на светильники, люстры и бра. (Иначе говоря, товар из класса ликвидности 5 перешел в класс ликвидности 4.) Если бы нашему предприятию были нужны люстры для собственного потребления или наши коммерсанты смогли бы реализовать все люстры за деньги, то цепочка на этом бы и прервалась. Но в крупных объемах так не получается (не забываем, что первоначальные владельцы товара тоже не смогли - по разным причинам - полностью реализовать его за деньги). Таким образом, вынужденно появляются следующие бартерные сделки.

Шаг 2. Обмен части люстр на холсты и подвесные системы для картин. Аля данного объема полученного товара бартерная цепочка финишировала, так как он будет использован для внутреннего потребления предприятием (в нашем примере - арт-галереей). В этом случае нас не интересует класс ликвидности полученного товара - он все равно наивысший, ведь не приди он по бартеру, нам бы пришлось тратить деньги на его покупку. 
Шаг 3. Продажа части люстр путем передачи их на реализацию с дисконтом в специализированные магазины.

Шаг 4. Обмен оставшихся люстр (товар класса 4) на домашний текстиль (товар класса 3). Таким образом, мы увеличили ликвидность нашего товара при той же глубине дисконта.

Шаг 5. Продажа части домашнего текстиля путем передачи его на реализацию в специализированные магазины.

Шаг 6. Обмен части домашнего текстиля на мольберты для проведения выставок. (См. комментарий к шагу 2. Единственное примечание - прежним владельцам мольбертов не нужны были люстры и картины, зато домашний текстиль понадобился.)

Шаг 7. Обмен остатка партии домашнего текстиля (класс 3) на автомобиль (класс 2) с последующей оперативной его продажей.

Важно не забывать, что указанные варианты оказались возможны в связи с тем, что бартерный оператор имел с самого начала выстраивания цепочки серьезный запас маржинальности, что и позволило ему, увеличив ликвидность, «выйти в деньги», оставив себе хорошую прибыль.

Понятно, что указанными шагами работа с люстрами, если их партия была большая, не ограничится. Может быть сколько угодно шагов, и прибыль от цепочки может поступать даже после того, как физически все люстры исчезнут со склада.

Кстати, пример с люстрами взят из нашего личного опыта. Нечасто на рынке меняют серьезную коллекцию картин на контейнер светильников, но ведь кто-то должен быть первым...

Из личного же опыта могу отметить, что дальнейшая серьезная работа с бартером весьма интересна в финансовом и научно-прикладном плане, но уже не имеет отношения к арт-бизнесу и будет описана автором в отдельной статье, для которой даже подобрано название: «Бридинговый маркетинг».

\section{ЗАКАЮЧЕНИЕ}

Опыт последних лет работы показывает, что введение в арсенал арт-галереи возможности бартерных сделок резко увеличивает экономическую устойчивость галереи. Здесь действуют две противоположно направленные тенденции. Чем сильнее явления кризиса и стагнации, тем хуже арт-бизнесу (я постоянно имею в виду современное искусство), поскольку живопись и графика - не предметы первой необходимости. Однако именно при кризисных явлениях резко интенсифицируются именно бартерные операции. Следует подготовиться к документальному оформлению бартерных операций и их налогообложению. Необходимо также введение торговых операций в число допустимых для данного предприятия, так как чаще всего бартер документируется как встречные сделки купли-продажи на равную сумму.

Бартер допустим только при наличии высокомаржинального товара. Поэтому если речь идет об арт-галерее, то бартер невозможен, например, с картинами малоизвестных «недорогих» авторов или с товарами, взятыми на комиссию, за исключением бартера на жизненно необходимый галерее товар. Бартерные операции в арт-бизнесе позволяют улучшить финансовые показатели галереи, правда, за счет весьма серьезного повышения трудоемкости бизнеса и готовности к нестандартным решениям. Могут иметь место смешанные операции, когда часть суммы за картину выплачивается деньгами, а оставшаяся часть - бартером. С другой стороны бартерной сделки (если речь идет об обмене картин на товар) находится, как правило, неподготовленный в ис- 
кусствоведческом плане человек. Это усложняет общение, но увеличивает круг потенциальных клиентов. Бартерные сделки сильно увеличивают трафик галереи. Этому же способствует включение в «бартерный портфель» ранее полученных непроданных товаров: приходят посмотреть на них, а смотрят и на искусство тоже. И покупают. Бартерные сделки позволяют прозрачно документировать высокие цены на искусство. Бартерные сделки приводят к появлению на балансе галереи множества «несвойственных» ей товаров, поэтому следует либо организовать внутри галереи соответствующее направление, либо скооперироваться на сбыте этих товаров с профессиональным торговым предприятием.

При использовании бартерных сделок в общем случае (не на одних лишь примерах арт-бизнеса) перед бизнесом ставится не только главная задача - извлечение конечной прибыли, но и постоянная вспомогательная: бартерная конвертация максимально возможной части товарных запасов в сторону повышения ликвидности.

Существует опасность репутационных потерь от бартерных операций с ВНТУ, о чем надо постоянно помнить бизнес-оператору. Она связана с возможным ощущением того, что данный товар его владелец готов обменять на что угодно, и, соответственно, этот товар опасен для бизнеса. Следует отказываться от сделок, могущих нанести репутационный ущерб, так как высокая маржинальность ВНТУ держится как раз на репутационной составляющей. Аля избегания подобных опасностей категорически не следует соглашаться на бартерные сделки по заниженной стоимости ВНТУ либо распродавать полученный по бартеру за ВНТУ товар со скидками, заметно превышающими традиционные рыночные.

И главный вывод. Практически все сказанное здесь имеет отношение не только к арт-бизнесу. Бартер - мощное средство интенсификации сбыта в любом бизнесе, в котором имеются товары и услуги с высокой маржинальностью, либо где необходим быстрый «сброс» товарных позиций, либо где нехватка денежных средств при наличии товарных запасов грозит существованию бизнеса.

Недостатки бартера заключаются в необходимости освоения непрофильных компетенций и опасности репутационных потерь. Автор не зря взял в качестве основного примера арт-индустрию современного искусства - здесь без новых подходов, особенно при углублении экономического кризиса, несомненно, разорится большая часть сегодняшних операторов рынка. Таким образом, новые методы интенсификации сбыта - это не игра ума университетских ученых, а просто насущная необходимость, диктуемая временем.

\section{ПРИМЕЧАНИЕ}

1 Безымянные картины.

\section{СПИСОК АИТЕРАТУРЫ}

Богданов, В. (2013) Некоторые примеры неудачных инвестиций в искусство [Электронный pecypc] // ARTinvestment.RU. Инвестиции в искусство. 4 февраля. URL: http://forum.artinvestment.ru/blog.php?b=227855 [архивировано в WebCite] (дата обращения: 7.05.2015).

Гольман, И. А. (2004) Рекламная деятельность: планирование, технологии, организация. 3-е изд., перераб. и доп. М. : Гелла-принт. 352 с. (Сер. «Рекламные технологии»).

Гольман, И. А. (2013а) Искусство как товар: парадоксы и закономерности // Знание. Понимание. Умение. № 2. С. 205-212.

Гольман, И. А. (2013b) Российский арт-рынок современного искусства с точки зрения маркетолога // Знание. Понимание. Умение. № 4 С. 195-201. 
Гольман, И. А. (2014а) Критерии выбора современного художника для активного и пассивного инвестирования на арт-рынке // Знание. Понимание. Умение. № 4. С. 137-147.

Гольман, И. А. (2014b) Разработка специального курса «Современный арт-маркетинг» // XVIII Международная конференция заведующих кафедрами маркетинга, рекламы, связей с общественностью и смежных специальностей. Москва, 17-19 апреля 2014 г.: сб. материалов / под общ. ред. В. А. Евстафьева. М. : Ассоциация коммуникационных агентств России. С. 145-154.

Котлер, Ф. (1990) Основы маркетинга. М. : Прогресс. 736 с.

Сапунков Игорь [Электронный ресурс] // Совком. Аукционный дом. URL: http://sovcom.ru /index.php?category=painters\&painterstype=painter\&painter $=2065$ [архивировано в WebCite] (дата обращения: 12.05.2015).

Aата поступления: 13.06 .2015 2.

\section{SALES INTENSIFICATION OF HIGH-MARGIN LOW LIQUID GOODS BY BARTER TRANSACTIONS (ILLUSTRATED BY THE EXAMPLE OF THE ART BUSINESS) \\ I. A. GOLMAN \\ (MOSCOW UNIVERSITY FOR THE HUMANITIES)}

The article singles out and examines as a separate class of commercial products the cluster of highmargin low liquid goods and services (HMLLGS). General problems of sales intensification, related to similar products, were studied from the point of view of a practicing marketing expert, taking into account the signs of a crisis in the economy as well.

The topic is evidently of great current interest, given that the volume of Russian market of HMLLGS amounts to tens of billions of roubles and has a tendency to grow even further. At the same time this cluster in particular is highly sensible to the signs of a crisis in the economy. The author, on the basis of his own economic experiments, examines the method of sales intensification of HMLLGS by using barter transactions. The mechanisms of barter transactions with HMLLGS are represented, as well as their advantages and shortcomings.

The modern Russian art business with its main products - paintings and graphic art - serves as an example of HMLLGS. The reasoning and the conclusions of the author are confirmed not only by his previous studies, dedicated to the art business and published in the journal "Znanie. Ponimanie. Umenie" ("Knowledge. Understanding. Skill"), but also by the results of his economic experiments, which haven't yet been published, including the barter transactions in the modern Russian art business. The benefits and drawbacks of this method of sales intensification are illustrated with certain examples, including the possibility of sales gain and acceleration, as well as the growth of labour intensity of the process, the need for the staff to acquire new skills sets, additional problems with taxation and the probability of reputational damage.

The scale of barter goods is introduced, based on the level of their liquidity, and examples of forming barter chains are provided. A conclusion is drawn, based on own experience of the author, that barter transactions, if used well, can considerably increase the economic efficiency not only of the art business, but of the whole cluster of HMLLGS.

Keywords: marketing, high-margin low liquid goods, cluster of HMLLGS, barter, barter transactions, art market.

\section{REFERENCES}

Bogdanov, V. (2013) Nekotorye primery neudachnykh investitsii v iskusstvo [Some examples of unsuccessful investments in art]. ARTinvestment.RU. Investitsii v iskusstvo. February 4 [online] Available at: http://forum.artinvestment.ru/blog.php? $\mathrm{b}=227855$ [archived in WebCite] (accessed 7.05.2015).

Golman, I. A. (2004) Reklamnaia deiatel'nost': planirovanie, tekbnologii, organizatsiia [Promotional activities: Planning, techniques and organization]. 3rd edn., revised and enlarged. Moscow, Gella-print Publ. 352 p. (Series "Reklamnye tekhnologii”). (In Russ.). 
Golman, I. A. (2013a) Iskusstvo kak tovar: paradoksy i zakonomernosti [Art as commodity: The paradoxes and common factors]. Znanie. Ponimanie. Umenie, no. 2, pp. 205-212. (In Russ.).

Golman, I. A. (2013b) Rossiiskii art-rynok sovremennogo iskusstva s tochki zreniia marketologa [The Russian market of modern art in terms of marketing]. Znanie. Ponimanie. Umenie, no. 4, pp. 195-201. (In Russ.).

Golman, I. A. (2014a) Kriterii vybora sovremennogo khudozhnika dlia aktivnogo i passivnogo investirovaniia na art-rynke [Criteria of selecting a contemporary artist for active and passive investment in the art market]. Znanie. Ponimanie. Umenie, no. 4, pp. 137-147. (In Russ.).

Golman, I. A. (2014b) Razrabotka spetsial'nogo kursa «Sovremennyi art-marketing» [Development of a special program of study "Modern Art Marketing"]. In: XVIII Mezbdunarodnaia konferentsiia zaveduiushchikb kafedrami marketinga, reklamy, sviazei s obsbchestvennost' iu $i$ smezhnykb spetsial' noste $i$ [The $18^{\text {th }}$ International conference of chairs of departments of marketing, advertising, PR and related professions]. Moscow, April 17-19 aprelia, 2014 : Proceedings / ed. by V. A. Evstafiev. Moscow, Assotsiatsiia kommunikatsionnykh agentstv Rossii [Association of Communication Agencies of Russia]. Pp. 145-154. (In Russ.).

Kotler, P. (1990) Osnovy marketinga [Marketing essentials]. Moscow, Progress Publ. 736 p. (In Russ.).

Sapunkov Igor' [Sapunkov Igor]. Sovkom. Auktsionnyi dom [online] Available at: http://sovcom.ru/index.php?category=painters\&painterstype $=$ painter\&painter $=2065$ [archived in WebCite] (accessed 12.05.2015). (In Russ.).

Submission date: 13.06.2015.

Гольман Иосиф Абрамович - кандидат технических наук, профессор кафедры теории рекламы и массовых коммуникаций Московского гуманитарного университета, креативный директор галереи «Арт-Гнездо». Адрес: 111395, Россия, г. Москва, ул. Юности, д. 5. Тел.: +7 (499) 374-54-51. Эл. aApec: i7591@yandex.ru

Golman Iosif Abramovich, Candidate of Technology, Professor, Department of Advertising Theory and Mass Communications, Moscow University for the Humanities; Creative Director, Art-Gnezdo Gallery. Postal address: 5 Yunosti St., 111395 Moscow, Russian Federation. Tel.: +7 (499) 374-54-51. E-mail: i7591@yandex.ru 